\title{
OPINIÃO DE MULHERES DE BAIXA RENDA, RESIDENTES EM CIDADE DO INTERIOR SOBRE PLANEJAMENTO FAMILIAR
}

\author{
Anamaria Carneiro* \\ Kazue Horigoshi Rodrigues**
}

\begin{abstract}
RESUMO. Apresenta opinião de mulheres de baixa renda, residentes em zona rural do interior, sobre concepção e contracepção; identifica o nível de conhecimento sobre planejamento familiar e demonstra os aspectos sócio-culturais que influenciam na opinião destas mulheres.
\end{abstract}

\begin{abstract}
The authors presents the opinion of low income women, dwellers of the countryside, about conception and contraception; identifies their level of information on family planning and demonstrates the socio-cultural aspects that influence the opinion of such women.
\end{abstract}

\section{INTRODUC̣ÃO}

É conhecido que a criança e a mãe são as duas camadas da população, prioritárias no atendimento de saúde devido ao seu alto índice de morbidade e mortalidade, principalmente nos paises em desenvolvimento.

Recentes estudos da OMS (1970) mostraram que a gravidez na adolescência, representa um alto risco para a saúde da mulher e da criança. De cada 1.000 crianças nascidas de mãe adolescente, na cidade de São Paulo, 104 morreram antes do 1 ? ano de vida. Da mesma forma a estatística tem demonstrado que a mortalidade materna é maior para mulheres que engravidam após 30 anos, assim como está comprovado um aumento de incidência de algumas anomalias congênitas, como mongolismo, entre filhos de gestantes de idade avançada. Já no quarto parto, a incidência de morte materna, aborto e mortalidade infantil começam a aumentar consideravelmente, e o parto depois do $5^{\circ}$. filho apresenta riscos crescentes.

Gestações sucessivas e muito próximas uma da outra podem ocasionar doença ou morte tanto da mulher como do concepto.

Estudos em famílias de baixa renda, de diferentes áreas do nordeste brasileiro, tem revelado que as crianças de famílias numerosas são mais vulneráveis à des- nutrição, doença e morte, aumentando esta vulnerabilidade entre os filhos mais novos.

Para atender a esse contingente feminino e infantil as organizações internacionais de saúde têm desenvolvido nos últimos anos a idéia de que a assistência materno-infantil deva ser organizada com critérios flexíveis, adaptados às necessidades, recursos e circunstâncias sociais e ambientais dos países em desenvolvimento.

No Brasil, verifica-se que dentre os grupos populacionais que recebem assistência médico-sanitária, $o$ grupo constituído pelas mulheres acima de 15 anos é o que talvez menos atenção tem recebido. Tradicionalmente a mulher tem sido atendida pelo sistema de saúde, quase que exclusivamente durante o período de ciclo grávido-puerperal, deixando-se em plano secundário todos os outros aspectos como a prevenção e diagnóstico de doenças ginecológicas, doenças transmitidas sexualmente, repercussão da gravidez não desejada, do aborto, e acesso a métodos de controle da fertilidade.

Sendo grande no Brasil o contingente de mulheres com baixo poder aquisitivo, residindo em regiões pobres em meios de comunicação e carentes de assistểncia médico-sanitária torna-se mais que necessário a implementação de programas de planejamento familiar que lhes leve não só a informação como também 0 acesso aos diferentes métodos contraceptivos.

* Professor Assistente 4 - Disciplina Enfermagem Médico-Cirúrgica - Universidade de Brasília.

** Professor Assistente 4 - Disciplina Enfermagem Pediátrica - Universidade de Brasília. 
Para BAI \& RATNAMALIKA, (1981) alguns métodos de educação ainda"que progressivos e construtivos podem não atingir os objetivos desejados se não levarem em consideração a atitude da população, e terminam dizendo que na Índia os promotores de planejamento familiar estão errando ao propor drásticas mudanças em todo o país.

Assim sendo este trabalho teve a finalidade de verificar a opinião de mulheres de baixa renda, residentes em região urbana do interior, sobre "Planejamento Familiar" no intuito de:

- Contribuir para a melhoria da assistência à mulher.

- Divulgar informações que possam orientar as ações de saúde quanto a grupos a serem prioritariamente atendidos e métodos a serem empregados em programas de planejamento familiar.

- Iniciar investigações sobre os aspectos que estão influindo na opiniẫo destas mulheres.

Destacamos como objetivos deste trabalho:

- Conhecer a opinião de mulheres de baixa renda em zona urbana do interior sobre a concepção e contracepção.

- Fornecer dados sobre seus conhecimentos quanto ao planejamento familiar que possam orientar as ações de saúde que visem a assistência à mulher.

- Identificar aspectos sócio-culturais que influenciam na opinião destas mulheres.

\section{METODOLOGIA}

\section{Local}

0 estudo foi realizado em área urbana do Município de Nova Xavantina em Mato Grosso.

O Município tem como estimativa de população 12.000 habitantes dos quais 8.000 em zona urbana. A economia é baseada na agropecuária com fazendas de grande porte pertencentes a grupos de empresas agropecuárias. Não há indústria no município e o comércio local é restrito.

A cidade não é servida por rede de esgotos e a eletricidade é fornecida por motores diesel com horários fixos de funcionamento no período noturno e 4 horas durante o dia, sendo que a rede elétrica só atende o centro da cidade. 0 abastecimento de água e precário, não atingindo os bairros.

A escolha deste município se deve ao fato de preencher os requisitos pré-estabelecidos quanto a precariedade dos meios de comunicação pois a cidade não dispõe de canais de TV nem capta imagem de municípios vizinhos, não tem jornal de circulação periódica e nem os recebe de outra cidade.

\section{População e Amostra}

A população foi constituída por mulheres em ida- de fértil (15 a 49 anos), residentes na área urbana de Nova Xavantina.

Da área urbana de Nova Xavantina foram selecionados três bairros onde se concentra a população de mais baixa renda, todos com características semelhantes: não possuem luz elétrica, água encanada, nem rede de esgoto. Grande número de casas de adobe, pau-apique ou lasca de madeira, algumas de palha. Na sua maioria cobertas de telhas de eternite. $O$ bairro $A$ dista do centro da cidade $2 \mathrm{~km}$, o $B$ dista $3 \mathrm{~km}$ e o $C 4 \mathrm{~km}$.

A prefeitura não dispõe de censo de produção ou caracterização dos bairros, portanto fizemos um levantamento do número de casas constatando: Bairro $A, 52$ casas; Bairro $B, 56$ casas e Bairro $C, 69$ casas. Deste total (176 casas) foram escolhidas 89 casa para receberem a visita do entrevistador, contando-se sempre dos dois lados da rua um intervalo de 1 casa entre as sorteadas.

Tratando-se de uma pesquisa exploratória com o fim de levantar problemas, e considerando-se a falta de recursos por ser o estudo financiado pelos próprios pesquisadores, o estudo atingiu 89 mulheres que constituem $50 \%$ do número de famílias residentes na área.

\section{Método}

Como instrumental foi utilizado um formulário para as entrevistas contendo:

1. parte - Identificação e características sócio-econômicas da entrevistada.

$2^{\mathrm{a}}$. parte - Informações referentes à concepção.

$3^{\text {a }}$ parte - Conhecimentos específicos referentes à contracepção.

A coleta de dados foi feita através de entrevistas em visitas domiciliares, pelo pesquisador e os dados obtidos foram tabulados manualmente e tratados com freqüência absoluta e relativa.

\section{APRESENTAC̣ÃO DOS DADOS}

Quanto a caracterização da amostra, procuramos apresentar aqui alguns dados que nos chamaram mais a atenção:

QUADRO 1 - Características sócio-econômicas da amostra

\begin{tabular}{|lr|}
\hline Idade: 15 a 30 anos & $58,4 \%$ \\
Estado Civil: casadas & $53,9 \%$ \\
Tempo de união: mais de 9 anos & $50,5 \%$ \\
Grau de instrução da entrevistada: analfabeta & $37,0 \%$ \\
Ocupação da entrevistada: dona de casa & $79,8 \%$ \\
Renda Familiar: & \\
Até 1 salário-mínimo: & $40,5 \%$ \\
Não souberam informar & $39,3 \%$ \\
No de pessoas que vivem na casa: 7 pessoas ou mais $33,8 \%$ \\
No de cômodos das casas: entre 4 e 5 cômodos & $38,2 \%$ \\
Religião da entrevistada: Católica & $83,1 \%$ \\
Naturalidade da entrevistada: Mato Grosso & $43,8 \%$ \\
\hline
\end{tabular}


Do quadro anterior gostaríamos de destacar que mais da metade da amostra é constituída de mulheres jovens e casadas há mais de 9 anos.

Evidencia-se o baixo nível de instrução com 37,0\% de analfabetas e apesar da baixa renda familiar, considerando que 40,5\% recebe até 1 salário-mínimo, as mulheres não contribuem para aumentar esta renda uma vez que $79,8 \%$ são donas-de-casa além do que desinformadas pois $39,3 \%$ não souberam informar qual a renda da família. Compatível com a baixa renda e o nível de escolaridade, encontramos famílias grandes sendo $33,8 \%$ com mais de 7 pessoas, muitas delas com 10 a 15 pessoas, em habitações pequenas com o maior índice de 4 a 5 cômodos $(38,2 \%)$ e as demais residências com menor número de cômodos.

Grande percentagem $(83,1 \%)$ das entrevistadas diz ser católica e quase a metade delas $(43,8 \%)$ é natural do mesmo estado, Mato Grosso, sendo seguida pelas que vieram de Goiás $(31,4 \%)$.

Quando questionamos sobre o acesso aos meios de comunicação $39,3 \%$ das entrevistadas não têm acesso a nenhum deles e $60,7 \%$ possuem rádio. Nenhuma delas lê revistas ou jornais.

\section{DADOS REFERENTES À CONCEPC̣ÃO}

TABELA 1 - Número de gravidez da entrevistada até o momento da entrevista.

\begin{tabular}{|c|c|c|}
\hline Quantas vezes engravidou & $\mathrm{F}$ & $\%$ \\
\hline 0 & 14 & 15,7 \\
\hline 1 & 04 & 4,5 \\
\hline 2 a 3 & 25 & 28,1 \\
\hline 4 a 5 & 20 & 22,5 \\
\hline 6 a 7 & 08 & 9,0 \\
\hline+ de 7 & 18 & 20,2 \\
\hline TOTAL & 89 & 100,0 \\
\hline
\end{tabular}

TABELA 2 - Número de filhos vivos no momento da entrevista.

\begin{tabular}{|c|r|r|}
\hline No. de filhos vivos & F & $\%$ \\
\hline 0 & 14 & 15,7 \\
1 & 09 & 10,1 \\
2 a 3 & 28 & 31,5 \\
4 a 5 & 24 & 27,0 \\
6 a 7 & 06 & 6,8 \\
+ de 7 & 08 & 8,9 \\
\hline TOTAL & 89 & 100,0 \\
\hline
\end{tabular}

Se compararmos as tabelas 1 e 2 verificamos que, embora $31,5 \%$ das entrevistadas tenham 2 a 3 filhos apenas $28,1 \%$ delas engravidou entre 2 e 3 vezes, enquanto $20,2 \%$ engravidou mais de 7 vezes e apenas,
8,9\% tem mais de 7 filhos. A mesma discrepância pode ser observada quanto as que engravidaram 4 a 5 vezes e as que têm este número de filhos, levando-nos a perceber que o número de filhos é inferior ao número de gravidez e portanto indicativo de gravidez que não chegou a termo.

Verifica-se ainda na tabela 2 que o maior índice $31,5 \%$ recai sobre 2 a 3 filhos vivos seguido de $27,0 \%$ para 4 a 5 filhos. Incidência semelhante foi encontrada quando se questionou a opinião das mulheres sobre o número de filhos que um casal deveria ter, quando os maiores percentuais $48,3 \%$ e $28,1 \%$ recaíram respectivamente sobre 2 a 3 filhos e 4 a 5 filhos.

Existe portanto, na amostra estudada, uma certa coerência entre $o \mathrm{n}^{0}$. de filhos que consideram ideal e $o \mathrm{n}$. de filhos que possuem, permitindo-nos levantar a hipótese de que muitas delas tiveram apenas os filhos que pretendiam.

No entanto, são bem diversificadas as opiniões referentes a quem compete a decisão quanto ao número de filhos que o casal deve ter:

TABELA 3 - Opinião das entrevistadas sobre a quem compete a decisão quanto ao $\mathrm{n}$ ? de filhos que o casal deve ter.

\begin{tabular}{|l|r|r|}
\hline Decisão quanto a número de filhos compete: & F & $\%$ \\
\hline A mulher & 21 & 23,6 \\
Ao marido & 10 & 11,2 \\
Ao casal & 24 & 27,0 \\
Ao médico & 05 & 5,6 \\
A Deus & 24 & 27,0 \\
Outros & 05 & 5,6 \\
\hline TOTAL & 89 & 100,00 \\
\hline
\end{tabular}

Na tabela 3 chama-nos a atenção o fato de que $27,0 \%$ das entrevistas atribui a decisão sobre o número de filhos a Deus e igual número atribui ao casal.

Um número significativo de entrevistadas, se consideramos a distribuição das respostas, atribui a decisão quanto ao número de filhos somente à mulher (23,6\%). Embora apenas $38,2 \%$ tenham considerado a participação do cônjuge, $46,1 \%$ das entrevistadas já conversou com o companheiro sobre 0 assunto.

\section{DADOS REFERENTES À CONTRACEPC̣ÃO}

Quando perguntamos se concordavam ou não com os casais que planejam a família evitando filhos fora deste planejamento $67,4 \%$ das entrevistadas concordam com este procedimento e como razão para tal, $46,7 \%$ delas alegaram que o atual custo de vida é muito alto não permitindo alimentar os filhos enquanto $26,7 \%$ mulheres que não concordam com este procedimento mais da metade alega como razão para discor- 
dar, o fato de tal atitude "ser contra Deus". Gostaríamos ainda de destacar que $13,8 \%$ das que não concordam que os casais evitem filhos, o fazem por considerar que 'evitar filhos faz a mulher adoecer'.

Indagamos das entrevistadas se já tinham ouvido falar de métodos contraceptivos e 78,7\% delas responderam afirmativamente. A seguir, pedimos que citassem os que já tinham ouvido falar e depois apresentamos uma listagem pedindo que citassem quais deles já conheciam, a medida que íamos citando cada um.

QUADRO 2 - Métodos contraceptivos citados como conhecidos pelas entrevistadas.

\begin{tabular}{|l|c|c|c|c|}
\hline \multirow{2}{*}{$\begin{array}{c}\text { Método } \\
\text { contraceptivo }\end{array}$} & \multicolumn{2}{c|}{$\begin{array}{c}\text { Citações sem } \\
\text { listagem prévia }\end{array}$} & \multicolumn{2}{c|}{$\begin{array}{c}\text { Citações com } \\
\text { listagem prévia }\end{array}$} \\
\cline { 2 - 5 } & $\mathrm{F}$ & $\%$ & $\mathrm{~F}$ & $\%$ \\
\hline Contraceptivos & 67 & 75,3 & 80 & 90,0 \\
$\quad$ Orais & 08 & 9,0 & 63 & 70,8 \\
Condom & - & - & 10 & 11,2 \\
Espermicidas & 12 & 13,5 & 77 & 86,5 \\
Aborto & 20 & 22,4 & 82 & 92,1 \\
Esterilização & 05 & 5,6 & 19 & 21,3 \\
Tabela & 01 & 1,1 & 39 & 43,8 \\
Coito & - & - & 08 & 9,0 \\
$\quad$ interrompido & 09 & 10,1 & 25 & 28,1 \\
Diafragma & 07 & 7,9 & 58 & 65,2 \\
DIU & 19 & 21,4 & 02 & 2,2 \\
Ducha & & & & \\
Nenhum & & & & \\
Outros: ervas e & & & \\
$\quad$ raizes do & & 31,4 & 29 & 32,6 \\
$\quad$ mato, & & & & \\
$\quad$ remédios & caseiros e & & & \\
$\quad$ simpatias. & & &
\end{tabular}

Observação: 0 percentual foi calculado sobre o total de entrevistadas, uma vez que a pergunta permitia mais de uma resposta.

O estudo do Quadro 2 evidencia que o método contraceptivo mais conhecido é o oral pois foi citado por $75,3 \%$ das mulheres sem que lhes apresentasse a listagem de métodos subindo para $90 \%$ com a listagem.

Os condons foram citados espontaneamente por $9,0 \%$ e o coito interrompido por $1,1 \%$, no entanto estes percentuais subiram, respectivamente para $70,8 \%$ e $43,8 \%$ quando apresentada a listagem o que nos parece indicar o constrangimento das entrevistadas para mencionar a iniciativa masculina na contracepção.

0 aborto e a esterilização, não são tidos pelas entrevistadas como "maneiras de não pegar filho' uma vez que apenas $13,5 \%$ citou o aborto como tal e $22,4 \%$ citou a "ligadura", no entanto da listagem apresentada por nós $86,5 \%$ das mulheres disseram ter ouvido falar do aborto e $92,1 \%$ da esterilização. A utilização de ervas e raízes na contracepção é conhecida praticamen- te pelo mesmo número de mulheres: $31,4 \%$ sem a listagem e $32,6 \%$ após a listagem.

No que se refere ao interesse em praticar métodos contraceptivos, $57,3 \%$ das entrevistadas não tem interesse em praticar nenhum deles. Destas, $27,5 \%$ já se submeteram a esterilização voluntária e $22,6 \%$ não são férteis. Das $42,7 \%$ que gostariam de praticar métodos contraceptivos. 0 método sobre o qual recai o maior percentual é a esterilização $44,7 \%$ seguido dos contraceptivos orais com $13,2 \%$. Dentre as razões alegadas para preferir a esterilização estão:

- é mais seguro: $41,2 \%$

- é mais fácil e para sempre: $35,3 \%$

A preocupação com a segurança do método, para as que pretendem submeterem-se a esterilização, nos parece significativa, bem como relevante o percentual que está ciente da irreversibilidade do método.

Embora a grande maioria já tenha ouvido falar sobre métodos contraceptivos $65,2 \%$ gostaria de receber mais informações sobre os mesmos, e como meio de informação 29,3\% delas preferem recebê-las em reuniões de mulheres e $22,4 \%$ através de visita domiciliar. Evidencia-se, assim, o interesse em conhecer melhor os métodos contraceptivos, bem como a preferência por métodos de ensino que permitem maior proximidade com 0 orientador da aprendizagem.

Ressaltamos ainda o fato de que mesmo entre as que não têm interesse em contracepção existe $o$ interesse em conhecê-la, já que $65,2 \%$ deseja mais informações e apenas $42,7 \%$ tem interesse em praticá-la. Quanto à pratica de contracepção encontramos que $47,2 \%$ não utilizam nenhum método contraceptivo e $52,8 \%$ os utilizam.

TABELA 4 - Métodos contraceptivos eleitos pela parcela da população estudada que pratica a contracepção.

\begin{tabular}{|l|l|r|}
\hline \multicolumn{1}{|c|}{ Métodos contraceptivos utilizados } & F & $\%$ \\
\hline Contraceptivos orais & 05 & 10,6 \\
Esterilização feminina & 35 & 74,5 \\
Remédio caseiro & 02 & 4,3 \\
Ducha & 03 & 6,4 \\
Simpatia & 01 & 2,1 \\
Condom & 01 & 2,1 \\
\hline TOTAL & 47 & 100,0 \\
\hline
\end{tabular}

Na tabela 4 observamos que das mulheres que utilizam a contracepção é altamente significativa a diferença entre o método de maior incidência (a esterilização feminina - 74,5\%) e o que vem a seguir (contracpetivos orais $-20,6 \%$ ). 
O método da tabela não é usado por nenhuma das entrevistadas, sendo muito baixo o emprego dos contraceptivos de barreira $(2,1 \%)$.

É evidente portanto, a preferência da população estudada pela esterilização feminina pois ao somarmos as freqüências absolutas das mulheres já submeteram a esterilização (35 mulheres) as que pretendem submeter-se a ela (17 mulheres) e calcularmos o percentual sobre o total de entrevistadas temos uma incidência de $58,4 \%$.

Analisando o predomínio de interesse pela esterilização feminina na amostra estudada, associado a falta de meios de comunicação, baixo nível de instrução, bem como a inexistência de programas de planejamento familiar, consideramos que este item merece uma investigação mais ampla e profunda. Das 35 mulheres participantes da amostra que se submeteram à esterilização feminina, $42,8 \%$ o fizeram por decisão própria, $28,5 \%$ por decisão do médico e $28,5 \%$ por decisão de parentes (incluindo-se aí o marido).

Diante destes dados questionamos:

Será que as mulheres de baixa renda recebem informação sobre todos os métodos contraceptivos?

Há uma preferência pela esterilização entre as mulheres de baixa renda?

Em caso de optar pela esterilização, entre os demais métodos contraceptivos, as mulheres de baixa renda têm o mesmo acesso a ele que as mulheres de maior poder aquisitivo?

\section{CONSIDERAC̣ÕES FINAIS}

De acordo com as necessidades de saúde, e dentro das diretrizes estabelecidas pelo governo, em agosto de 1974, no Congresso Mundial de população de Bucarest, ' ao Estado cabe proporcionar informações e serviços sobre a regulação da fertilidade e adotar medidas necessárias para a redução da mortalidade geral e especialmente infantil". Nesse sentido o Ministério da Saúde vem desenvolvendo esforços para serem implementadas atividades que contemplem a saúde da mulher em sua integridade e elaborou um documento denominado Programa Integral da Saúde da mulher em junho/83 com subsídios que refletiam a preocupação e o interesse em discuti-lo amplamente.

Já anteriormente em 1980 a Senadora Eunice Michiles em um pronunciamento no Senado Federal solicitava o exame prioritário do Programa de Planejamento Familiar "por se tratar de um assunto de maior interesse para a mulher brasileira" para ela, a execução de um plano com este objetivo deveria estar voltado para as peculiaridades regionais, devendo ser elaborado por brasileiros para o Brasil, capaz de formar consciência para que a decisão sobre a prole seja voluntária, consciente e responsável. Dizia ainda da sua preocupação maior, com o desconhecimento total de milhões de brasileiros dos métodos de regulação de sua fertilidade e que por isso recorria a curiosas que lhe provocaria 0 aborto ou, quando muito, recorre à farmácia.

É assim que há alguns anos nota-se o interesse das autoridades quanto o planejamento familiar, mas quando será atendido como um direito humano básico do indivíduo e do casal para decidir livre e responsavelmente o número e espaçamento de seus filhos?

Não pode haver decisão sem conhecimento de opções, portanto para exercer o direito de decidir sobre a prole, o casal deve ter acesso à informação, educação e serviços de planejamento familiar.

\section{REFERÊNCIAS BIBLIOGRÁFICAS}

1. BAI, I.K. \& RATNAMALIKA, D.P. • Attitudes and beliefs concerning child care among women of Tirupati, Chittoon District, Andhra Pradesh, India. T. of Trop. Pediatrics. 27(10): 250-4, 1981.

2. FERNANDES, NORA I $\bullet$ Educación y planificación familiar en el setor urbano, Hygie, Paris, 3(2): 38-40, 1984.

3. HATCHER, R.A. et alii • Planejamento familiar • 10. ed., Rio de Janeiro, Ao Livro Técnico, 1983.

4. JOHNS HOPKINS UNIVERSITY, Population Information Reports, Hampton Hause, 1985 (Série y., $\mathrm{n}^{0} 27$ ).

5. ORGANIZACION MUNDIAL DE LA SALUD. Aspectos Sanitarios de la Planificación Familiar. Genebra, 1970. (Série de Informes Técnicos, $\mathrm{n}^{0}$. 442) 